\title{
ANALISIS KESULITAN SISWA SMA DENGAN GAYA BELAJAR VISUAL DALAM MENYELESAIKAN SOAL HOTS
}

\author{
Prasetyo B. Darmono ${ }^{1}$, Mei Wijayadi ${ }^{2}$, Nila Kurniasih ${ }^{3}$ \\ Program Studi Pendidikan Matematika, Universitas Muhammadiyah Purworejo ${ }^{1,2,3}$ \\ Email: meiwijayadi1@gmail.com
}

\begin{abstract}
Abstrak
Kesulitan siswa dalam menyelesaikan soal HOTS disebabkan beberapa faktor. Salah satu faktor penyebabnya yaitu gaya belajar. Gaya belajar siswa dibedakan menjadi tiga jenis, yaitu: visual, auditorial dan kinestetik. Gaya belajar yang dibahas dalam penelitian ini yaitu gaya belajar visual. Penelitian ini menggunakan metode kualitatif dan tujuan penelitian ini untuk mendeskripsikan kesulitan siswa dalam menyelesaikan soal HOTS dengan meninjau dari gaya belajar visual. Subjek penelitian diambil dengan teknik snowball sampling dan purposive sampling. Penelitian ini menggunakan teknik pengumpulan data berupa kuisioner, tes, wawancara, dan catatan lapangan. Penelitian ini dilakukan pada siswa kelas X MIPA 1 dan X MIPA 3 pada bulan April 2021. Data dianalisis dengan reduksi data, penyajian data, dan penarikan kesimpulan. Hasil penelitian ini adalah siswa yang memiliki gaya belajar visual mengalami kesulitan pada tahap menggunakan konsep pada soal dengan tingkat C6. Hal ini disebabkan siswa tidak terbiasa dengan soal HOTS.
\end{abstract}

Kata Kunci : Kesulitan Siswa, Visual, HOTS, Gaya Belajar

\begin{abstract}
The difficulties of student in solving HOTS problems are caused by some factors. One of them is student learning style. Student learning styles are divided into three types, namely visual, auditorial, and kinesthetics. This research focuses on visual learning style. This research uses a qualitative method aiming to describe the difficulties of student in solving HOTS mathematic problems by visual learning style. The subject was taken using snowball sampling and purposive sampling technique. The data collection techniques were questionnaire, test, interview, and note range. Analysis techniques used on in this research were data reduction, data display and conclusion drawing. The result of this research was student who had a visual learning style got difficulty in using concept at problem with C6 grade. That was because the students were not familiar with HOTS problems.
\end{abstract}

Key Words : Student Difficulties, Visual, HOTS, Learning Style

\section{PENDAHULUAN}

Matematika adalah mata pelajaran yang diberikan ke siswa dengan jam pelajaran yang lebih dibandingkan yang lainnya. Hal tersebut dikarenakan oleh pentingnya matematika dalam kehidupan sehari-hari. Matematika adalah mata pelajaran yang penting karena ilmu matematika bersifat mendasar dan dapat digunakan secara luas dalam kehidupan manusia [1]. Namun, terkadang siswa masih menganggap matematika itu sulit [2]. Sehingga kemampuan siswa masih rendah, hal ini sejalan dengan pendapat yang menyatakan bahwa data yang telah ada sampai saat ini pada umumnya kemampuan siswa di Indonesia masih sangatlah rendah pada pemahaman informasi yang bersifat kompleks, penerapan, prosedur, analisis, teori, pemecahan masalah, dan investigasi [3]. Sehingga, perlu adanya penelitian lebih lanjut tentang kesulitan siswa dalam menyelesaikan soal HOTS dalam matematika ditinjau dari gaya belajar visual, dengan demikian dapat diberikan masukan agar kesulitan tersebut dapat dikurangi. Meskipun telah ada penelitian tentang kesulitan siswa, namun dalam penelitian ini dibahas jika ditinjau dari gaya belajar visual secara lebih khusus. Menurut Cooney, dkk. dalam, kesulitan siswa mempelajari matematika dibedakan menjadi 3 jenis kesulitan, yaitu kesulitan pada memahami konsep, menggunakan 
prinsip dan menyelesaikan masalah verbal [4]. Siswa dapat mengalami kesulitan pada salah satu dari ketiga jenis tersebut atau bahkan beberapa kesulitan. Berikut indikator kesulitan siswa.

Tabel 1. Indikator Kesulitan Siswa

\begin{tabular}{|c|c|c|}
\hline No. & Jenis Kesulitan & Indikator \\
\hline 1. & $\begin{array}{l}\text { Kesulitan pada } \\
\text { tahap } \\
\text { memahami } \\
\text { konsep }\end{array}$ & $\begin{array}{l}\text { a. Ketidakmampuan dalam menyatakan arti istilah yang mewakili suatu } \\
\text { konsep. } \\
\text { b. Ketidakmampuan dalam mengingat suatu kondisi yang dapat dikaitkan } \\
\text { dengan konsep. } \\
\text { c. Ketidakmampuan dalam mengelompokkan objek sebagai contoh suatu } \\
\text { konsep. } \\
\text { d. Ketidakmampuan dalam menyimpulkan informasi yang diberikan dalam } \\
\text { sebuah konsep. }\end{array}$ \\
\hline 2. & $\begin{array}{l}\text { Kesulitan dalam } \\
\text { menggunakan } \\
\text { konsep }\end{array}$ & $\begin{array}{l}\text { a. Ketidakmampuan dalam menemukan hasil suatu perhitungan. } \\
\text { b. Kurang teliti dalam melakukan perhitungan. } \\
\text { c. Ketidakmampuan dalam mengabstraksi pola-pola dalam soal. } \\
\text { d. Ketidakmampuan mengutarakan prinsip atau konsep yang diketahuinya. }\end{array}$ \\
\hline 3. & $\begin{array}{l}\text { Kesulitan dalam } \\
\text { penyele-saian } \\
\text { masalah verbal }\end{array}$ & $\begin{array}{l}\text { a. Ketidakmampuan dalam menerjemahkan bahasa verbal ke bahasa } \\
\text { matematika. } \\
\text { b. Ketidakmampuan dalam menyelesaikan masalah dalam soal cerita. }\end{array}$ \\
\hline
\end{tabular}

Kesulitan siswa disebabkan oleh siswa kurang memahami materi, sehingga pembelajaran yang dilakukan dapat dikatakan tidak berhasil/ sukses. Kesuksesan pembelajaran dipengaruhi oleh peran orang tua, guru, strategi pembelajaran yang digunakan, dan sebagainya. Gaya belajar juga mempengaruhi kesuksesan pembelajaran, menurut hasil penelitian yang menyatakan bahwa gaya belajar mempengaruhi prestasi belajar siswa [5]. Gaya belajar adalah gabungan dari bagaimana orang tersebut menyerap dan kemudian mengolah informasi yang telah dia dapatkan [6]. Gaya belajar adalah kumpulan kebiasaan dari karakteristik seseorang dalam proses belajar mereka [7]. Disebutkan bahwa terdapat 3 (tiga) jenis gaya belajar, yaitu visual, auditorial, dan kinestetik. Penelitian ini hanya membahas tentang gaya belajar visual karena kebanyakan siswa di dalam kelas yang diteliti yang memiliki gaya belajar visual memperoleh nilai menengah ke bawah. Berikut indikator jenis gaya belajar visual:

Tabel 2. Indikator Gaya Belajar Visual

\begin{tabular}{lll}
\hline Gaya Belajar & & \multicolumn{1}{c}{ Indikator } \\
\hline & 1. & Rapi dan teratur. \\
& 2. & Teliti. \\
3. & Lebih mengingat hal-hal yang dilihat daripada yang hal-hal yang didengar. \\
Visual & 4. & Tidak terganggu dengan situasi yang tidak tenang. \\
& 5. & Membaca dengan tekun dan cepat. \\
& 6. & Lebih senang membaca sendiri daripada dibacakan orang lain. \\
& 7. & Membuat coretan-coretan tanpa makna yang jelas pada waktu berbicara \\
& & ketika rapat dan telepon. \\
\hline
\end{tabular}

Ketika pendidik dapat menyesuaikan pembelajarannya dengan gaya belajar siswa, maka pembelajaran dapat berjalan lancar dan tercapai tujuan pembelajaran sesuai perencanaan. Upaya lain yang dilakukan untuk meningkatkan kemampuan siswa yaitu pemberian soal dengan tingkat HOTS (Higher Order 
Thinking Skills) atau soal dengan tingkat kemampuan berpikir yang paling tinggi. Hal ini sesuai dengan pernyataan Amalia bahwa pentingnya HOTS dalam pendidikan matematika yaitu siswa dapat memahami matematika dengan baik [8]. HOTS adalah proses berpikir yang mengharuskan siswa untuk memanipulasi informasi dan ide-ide dalam cara tertentu yang memberi mereka pengertian dan implikasi baru. HOTS memuat berpikir kritis, logis, reflektif, metakognitif, dan kreatif yang merupakan kesulitan berpikir tingkat tinggi (King, dkk. dalam [9]). Hal tersebut sesuai dengan pernyataan bahwa HOTS memuat berpikir kritis dan berpikir kreatif [10]. Berdasarkan uraian tersebut, maka soal HOTS memuat kesulitan yang memerlukan kemampuan berpikir kritis, kreatif dan berpikir tingkat tinggi lainnya.Berikut indikator HOTS.

\section{Tabel 3. Indikator HOTS}

\begin{tabular}{|c|c|c|}
\hline No. & Tingkat kognitif & Indikator \\
\hline 1 & Menganalisis & $\begin{array}{l}\text { a. Analisis informasi yang diperoleh. } \\
\text { b. Menstruktur-kan informasi ke bagian-bagian kecil. } \\
\text { c. Mengidentifikasi faktor penyebab dari skenario atau sebuah rumus } \\
\text { digunakan. } \\
\text { d. Mengetahui akibat sebuah skenario atau rumus digunakan. } \\
\text { e. Merumuskan pertanyaan terkait informasi yang didapat. }\end{array}$ \\
\hline 2 & Mengevaluasi & $\begin{array}{l}\text { a. Menilai gagasan dengan kriteria yang telah ditentukan. } \\
\text { b. Membuat hipotesis terkait gagasan yang telah dinilai. } \\
\text { c. Memberikan kritik dan pengujian gagasan. } \\
\text { d. Memberi penerimaan atau penolakan gagasan }\end{array}$ \\
\hline 3 & Mencipta & $\begin{array}{l}\text { a. Membuat generalisasi gagasan terhadap sesuatu. } \\
\text { b. Merancang cara menyelesaikan masalah. } \\
\text { c. Mengorganisasikan bagian-bagian menjadi sebuah struktur baru. }\end{array}$ \\
\hline
\end{tabular}

\section{METODE}

Penelitian ini menggunakan metode kualitatif dan tujuan penelitian ini untuk mendeskripsikan kesulitan siswa dalam menyelesaikan soal HOTS dalam matematika dengan meninjau dari gaya belajar visual. Penelitian ini dilakukan di SMAN 3 Purworejo pada April 2021. Subjek penelitian ini yaitu siswa kelas $\mathrm{X}$ jurusan MIPA 1 dan MIPA 3, dengan mengambil 2 subjek penelitian. Subjek penelitian dipilih berdasarkan kuisioner gaya belajar dan pertimbangan guru.

Data dikumpulkan menggunakan kuisioner gaya belajar, tes dengan soal HOTS, catatan lapangan, wawancara, dan dokumentasi. Wawancara yang dilakukan berdasarkan indikator gaya belajar dan indikator kesulitan siswa yang telah dipaparkan pada Tabel 1 dan Tabel 2. Dalam penelitian ini digunakan teknik analisis data Miles \& Huberman yaitu data reduction, data display dan conlusion drawing [11].

\section{HASIL DAN PEMBAHASAN \\ Subjek $\mathrm{V}_{1}$}

Berdasarkan hasil pemberian kuisioner pada 27 Januari 2021, $\mathrm{V}_{1}$ adalah subjek dengan gaya belajar visual. Peneliti juga melakukan wawancara dan melaksanakan observasi sehingga diperoleh catatan lapangan untuk memastikan bahwa siswa tersebut benar-benar siswa gaya belajar visual.

Setelah diperoleh data dan bukti yang kuat tersebut, disimpulkan bahwa $\mathrm{V}_{1}$ adalah siswa dengan gaya belajar visual. Kemudian $\mathrm{V}_{1}$ diberikan tes dengan 3 soal HOTS. Tes diberikan kepada $\mathrm{V}_{1}$ pada tanggal 27 Februari 2021. Tes diberikan di luar jam pelajaran, sehingga tidak mengganggu pembelajaran siswa. Berikut dijelaskan pembahasan hasil tes $\mathrm{V}_{1}$. 


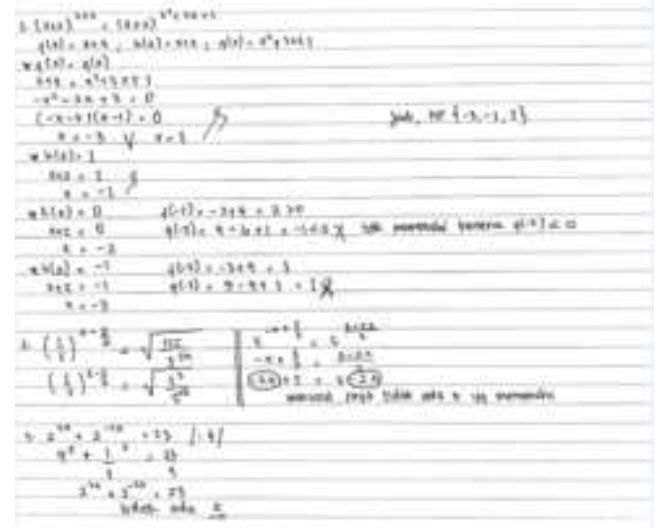

Gambar 1. Hasil Pengerjaan $V_{1}$

Terlihat dari hasil pengerjaan $\mathrm{V}_{1}$ rapi dan tertata dan mengerjakan semua soal sampai selesai. Setelah $\mathrm{V}_{1}$ mengerjakan tes, kemudian dilakukan wawancara tentang jawaban tes. Berdasarkan lembar jawaban, wawancara dan didukung catatan lapangan, $\mathrm{V}_{1}$ tidak merasa kesulitan pada soal nomor 1 dan nomor 2 yang merupakan soal dengan tingkat $\mathrm{C} 4$ dan $\mathrm{C} 5$ secara berturutturut. $\mathrm{V}_{1}$ tidak merasakan kesulitan karena sudah pernah menemui soal serupa. Sedangkan pada soal nomor 3 yang merupakan soal dengan tingkat $\mathrm{C} 6, \mathrm{~V}_{1}$ merasa kesulitan karena belum terbiasa dengan soal seperti itu namun sudah pernah menemui soal yang hampir mirip.

Kesulitan yang dialami $\mathrm{V}_{1}$ pada soal nomor 3 tergolong kesulitan tahap memahami konsep. Hal ini dapat dilihat dari ketidakmampuan dalam mengingat suatu kondisi yang dapat dikaitkan dengan konsep dan ketidakmampuan dalam menyimpulkan informasi yang diberikan dalam sebuah konsep. Sehingga $V_{1}$ juga tidak dapat menggunakan konsep yang harus digunakan untuk penyelesaian soal yang diberikan.

Selain jenis kesulitan yang dialami, berdasarkan hasil pengerjaannya, $\mathrm{V}_{1}$ tidak memenuhi indikator secara keseluruhan dalam penyelesaian soal HOTS. Berikut rinciannya:

1. Penyelesaian soal nomor $1, \mathrm{~V}_{1}$ hanya memenuhi beberapa indikator.
Indikator yang tidak dipenuhi yaitu analisis informasi yang diperoleh berupa menuliskan informasi dari soal dan merumuskan pertanyaan terkait informasi yang didapat berupa pemberian kesimpulan.

2. Penyelesaian soal nomor $2, \mathrm{~V}_{1}$ telah memenuhi semua indikator.

3. Penyelesaian soal nomor $3, V_{1}$ tidak memenuhi indikator secara keseluruhan.

\section{Subjek $\mathbf{V}_{2}$}

Berdasarkan hasil pemberian kuisioner pada 27 Januari 2021, $\mathrm{V}_{2}$ adalah subjek dengan gaya belajar visual. Gaya belajar tersebut mengandalkan penglihatannya dalam belajar. Peneliti juga melakukan wawancara dan melaksanakan observasi sehingga diperoleh catatan lapangan untuk memastikan bahwa siswa tersebut memiliki gaya belajar visual. Setelah diperoleh data dan bukti yang kuat tersebut, disimpulkan bahwa $\mathrm{V}_{2}$ adalah benar-benar siswa gaya belajar visual. Kemudian $\mathrm{V}_{2}$ dan diputuskan bahwa $\mathrm{V}_{2}$ adalah siswa gaya belajar visual, $\mathrm{V}_{2}$ diberikan tes dengan 3 soal HOTS. Tes diberikan kepada $\mathrm{V}_{2}$ pada tanggal 27 Februari 2021. Tes diberikan di luar jam pelajaran sekolah agar tidak mengganggu proses pembelajaran. Hasil tes $\mathrm{V}_{2}$ disajikan dalam gambar berikut.

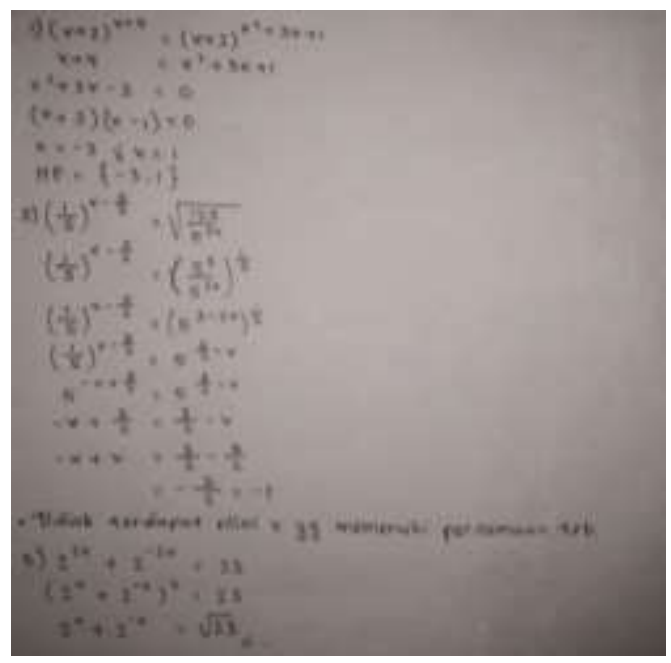

Gambar 2 Hasil Pengerjaan $\mathrm{V}_{2}$ 
Terlihat dari hasil pengerjaan $\mathrm{V}_{2}$ rapi dan tertata dan mengerjakan semua soal sampai selesai. Setelah $\mathrm{V}_{2}$ mengerjakan tes, kemudian dilakukan wawancara mengenai jawaban tes. Berdasarkan lembar jawaban, wawancara dan didukung catatan lapangan, $\mathrm{V}_{2}$ tidak merasa kesulitan pada soal nomor 1 yang merupakan soal dengan tingkat $\mathrm{C} 4$, namun terdapat jawaban yang masih kurang. $\mathrm{V}_{2}$ juga tidak merasa kesulitan pada soal nomor 2 yang merupakan soal dengan tingkat $\mathrm{C} 5$.

$\mathrm{V}_{2}$ tidak merasakan kesulitan karena sudah pernah menemui soal serupa. Sedangkan pada soal nomor 3 yang merupakan soal dengan tingkat $\mathrm{C} 6, \mathrm{~V}_{2}$ merasa kesulitan karena belum terbiasa dengan soal seperti itu namun sudah pernah menemui soal yang hampir mirip. Kesulitan yang dialami $\mathrm{V}_{2}$ pada soal nomor 3 tergolong kesulitan pada memahami konsep. Hal ini dapat dilihat dari ketidakmampuan dalam mengingat suatu kondisi yang dapat dikaitkan dengan konsep, ketidakmampuan dalam menyimpulkan informasi yang diberikan dalam sebuah konsep. Sehingga $\mathrm{V}_{2}$ juga tidak dapat menggunakan konsep yang harus digunakan dalam menyelesaikan soal tersebut.

Selain jenis kesulitan yang dialami, berdasarkan hasil pengerjaannya, $V_{2}$ tidak memenuhi indikator secara keseluruhan dalam penyelesaian soal HOTS. Berikut rinciannya:

1. Penyelesaian soal nomor $1, V_{2}$ hanya memenuhi satu indikator, yaitu mengetahui akibat dari sebuah skenario atau rumus yang digunakan yang berupa menentukan faktor dari persamaan kuadrat yang dihasilkan dari persamaan pangkat.

2. Penyelesaian soal nomor $2, \mathrm{~V}_{2}$ telah memenuhi semua indikator.

3. Penyelesaian soal nomor $3, V_{2}$ tidak memenuhi indikator secara keseluruhan.
Berdasarkan data yang telah dipaparkan, dapat disimpulkan bahwa siswa gaya belajar visual $\left(\mathrm{V}_{1}\right.$ dan $\left.\mathrm{V}_{2}\right)$ mengalami kesulitan pada tahap memahami konsep untuk soal dengan tingkat C6 disebabkan siswa tidak terbiasa dengan soal tersebut. Hal ini relevan dengan hasil penelitian yaitu kesulitan yang dialami siswa yaitu pada tingkat C6. Dengan demikian, hasil belajar siswa gaya belajar visual cukup baik, karena hanya kesulitan pada soal tingkat C6. Hasil penelitian ini diperkuat dengan hasil penelitian yang menyatakan bahwa kesulitan dalam menyelesaikan soal HOTS masih dialami siswa [12].

\section{SIMPULAN}

Berdasarkan hasil analisis data dari dua subjek penelitian, siswa gaya belajar visual mengalami kesulitan pada tahap memahami konsep. Kesulitan tersebut khususnya pada soal dengan tingkat C6. Kesulitan siswa tersebut disebabkan beberapa faktor, seperti kurangnya latihan soal, kurangnya mencari referensi jenisjenis soal pada materi eksponen. Hal tersebut mengakibatkan siswa tidak terbiasa dengan soal C6.

Kesulitan siswa ini menjadi penyebab tidak tercapainya semua indikator penyelesaian pada soal HOTS. Perlu diketahui bahwa tercapainya indikator penyelesaian pada soal HOTS ini sangat penting, karena hal tersebut dapat meningkatkan kemampuan siswa dan secara tidak langsung membantu memudahkan siswa dalam menyelesaikan permasalahan.

\section{DAFTAR PUSTAKA}

[1] Ernawati dan S. Sutiarso, "Analisis Kesulitan Menyelesaikan Soal Matematika Kategori Higher Order Thinking Skills". J. Penelit. Pembelajaran Mat., vol. 13, pp. 178195, 2020.

[2] S. Z. Sholihah dan A. A. Ekasatya, "Analisis Kesulitan Siswa dalam 
Proses Pemecahan Masalah Geometri Berdasarkan Tahapan Berpikir Van Hiele". J. Mosyarafa, vol. 6, 2017.

[3] P. P. Astutik. HOTS Berbasis PPK dalam Pembelajaran Tematik. Surabaya: Pustaka Media Guru, 2018.

[4] U. Dwidarti, H. L. Mampouw, dan D. Setyadi, "Analisis Kesulitan Siswa dalam Menyelesaikan Soal Cerita pada Materi Himpunan". J. Cendekia J. Pendidik. Mat., vol. 3, no. 2, pp. 315-322, 2019, doi: 10.31004/cendekia.v3i2.110.

[5] M. S. Rambe dan N. Yarni, "Pengaruh Gaya Belajar Visual, Auditorial, dan Kinestetik terhadap Prestasi Belajar Siswa SMA Dian Andalas Padang". Jurnal Review Pendidikan dan Pengajaran, vol. 2, pp. 291-296, 2019, [Online]. Available:

http://journal.universitaspahlawan.ac. id/index.php/jrpp.

[6] B. DePorter and H. Mike, Quantum Learning: Membiasakan Belajar Nyaman dan Menyenangkan. Bandung: Kafia, 2013.

[7] S. Jaleel and M. T. Anne, Learning Styles: Theories and Implications for Teaching Learning. USA: Horizon Research Publishing, 2019.

[8] H. Tambunan, "The Effectiveness of the Problem Solving Strategy and the Scientific Approach to Students' Mathematical Capabilities in High Order Thinking Skills". Int. Electron. J. Math. Educ., vol. 14, no. 2, pp. 293-302, 2019, doi: 10.29333/iejme/5715.

[9] A. S. Shidiq, M. Masykuri, dan E. Susanti, "Analisis Higher Order Thinking Skills (HOTS) Menggunakan Instrumen Two-Tier Multiple Choice pada Materi Kelarutan dan Hasil Kali Kelarutan untuk Siswa Kelas XI SMA N 1
Surakarta". Pros. Semin. Nas. Pendidik. Sains, no. November, pp. 2015-159, 2015.

[10] W. Conklin, Higher-Order Thinking Skills: to Develop 21st Learner. Shell Education, 2012.

[11] Sugiyono, Metode Penelitian Pendidikan: Pendekatan Kuantitatif, Kualitatif, dan $R \& D$. Bandung: Alfabeta, 2015.

[12] S. Hadi, H. Retnawati, S. Munadi, E. Apino, and N. F. Wulandari. "The Difficulties of High School Students in Solving Higher-Order Thinking Skills Problems". Problems Of Education In The $21^{\text {st }}$ Century. vol. 76, no. 4, pp 520-531, 2018. 